\title{
An Astronomer's Journey into Quantitative Reasoning
}

Jeffrey Bennett

Big Kid Science, jeff@bigkidscience.com

Follow this and additional works at: https://digitalcommons.usf.edu/numeracy

Part of the Curriculum and Instruction Commons, Higher Education Commons, and the Other Mathematics Commons

\section{Recommended Citation}

Bennett, Jeffrey. "An Astronomer's Journey into Quantitative Reasoning." Numeracy 14, Iss. 2 (2021): Article 4. DOI: https://doi.org/10.5038/1936-4660.14.2.1393 


\title{
An Astronomer's Journey into Quantitative Reasoning
}

\begin{abstract}
The University of Colorado Boulder campus introduced what may have been the world's first quantitative reasoning (QR) requirement in 1984 and started offering a QR course in 1988. Although I am an astronomer by training, I had the privilege of creating and teaching that course, which led to my coauthorship of the first textbook directed specifically at QR courses. In this "Roots and Seeds" piece, I will discuss how this course and textbook came to be, how I as an astronomer ended up involved in it, and how this work has connected with other aspects of my career.
\end{abstract}

\section{Keywords}

quantitative reasoning, textbooks, roots and seeds

Creative Commons License

(c) (1) (9)

This work is licensed under a Creative Commons Attribution-Noncommercial 4.0 License

\section{Cover Page Footnote}

Jeffrey Bennett is the lead author of the numeracy-focused textbooks Using and Understanding Mathematics - A Quantitative Reasoning Approach and Statistical Reasoning for Everyday Life, as well as of textbooks in astronomy and astrobiology, and of numerous books for children and the general public. He taught for decades at the University of Colorado, Boulder, and is the founder of Big Kid Science, dedicated to improving math and science literacy at all ages. He has won numerous awards for his writing, including the Science Communication Award from the American Institute of Physics. 
Human history becomes more and more a race between education and catastrophe. -H.G. Wells, 1920

I've started with the H.G. Wells quote because, whenever we look into the history of the movement for numeracy/quantitative literacy/quantitative reasoning (which for convenience I'll refer to as QR), I think it's important to remind ourselves why we are doing the work that we do. With that context in mind, I've been asked to provide a "roots and seeds" piece to explain how I, as an astronomer, ended up teaching a QR course way back in 1988 and writing (with Bill Briggs, who has a companion piece in this issue) the first textbook aimed directly at such courses, and also to explain how my work in QR ties in with other projects I've been involved with. To keep this long story fairly brief, I will divide this paper into four sections: my personal back story, the development of our quantitative reasoning course at the University of Colorado starting in the 1980s, the evolution of our QR textbook, and the connections with other aspects of my career.

\section{Brief Personal Back Story}

My personal involvement with QR traces back to what would now be called a "gap year" that I took between my first and second years of college. I was already very interested in teaching, so I used this year to work as a teaching assistant in a grades 2-3 elementary school classroom (Sunset View Elementary, San Diego). Given my math/science college path (I majored in Biophysics at UC San Diego), I was given fairly free reign to create math/science activities for these young kids, and in retrospect, many of these were very much in the QR spirit. I kept volunteering in this same classroom during my remaining 3 years of college, and also started and ran a math/science summer school for elementary and middle school kids. It was for this summer school that I began to develop a lot more QR material, since I recognized that even those kids who were very good at calculations needed a lot of help in understanding and interpreting mathematics.

One of my summer school projects was having the kids make scale models of the solar system, which to me are one of the best ways to provide a true sense of perspective on our planet Earth and our place as humans in a vast universe. A scale model solar system is itself a QR activity (e.g., scaling, modeling, interpreting large numbers), and such models can also be used to support many related QR activities (see Fig. 1). 


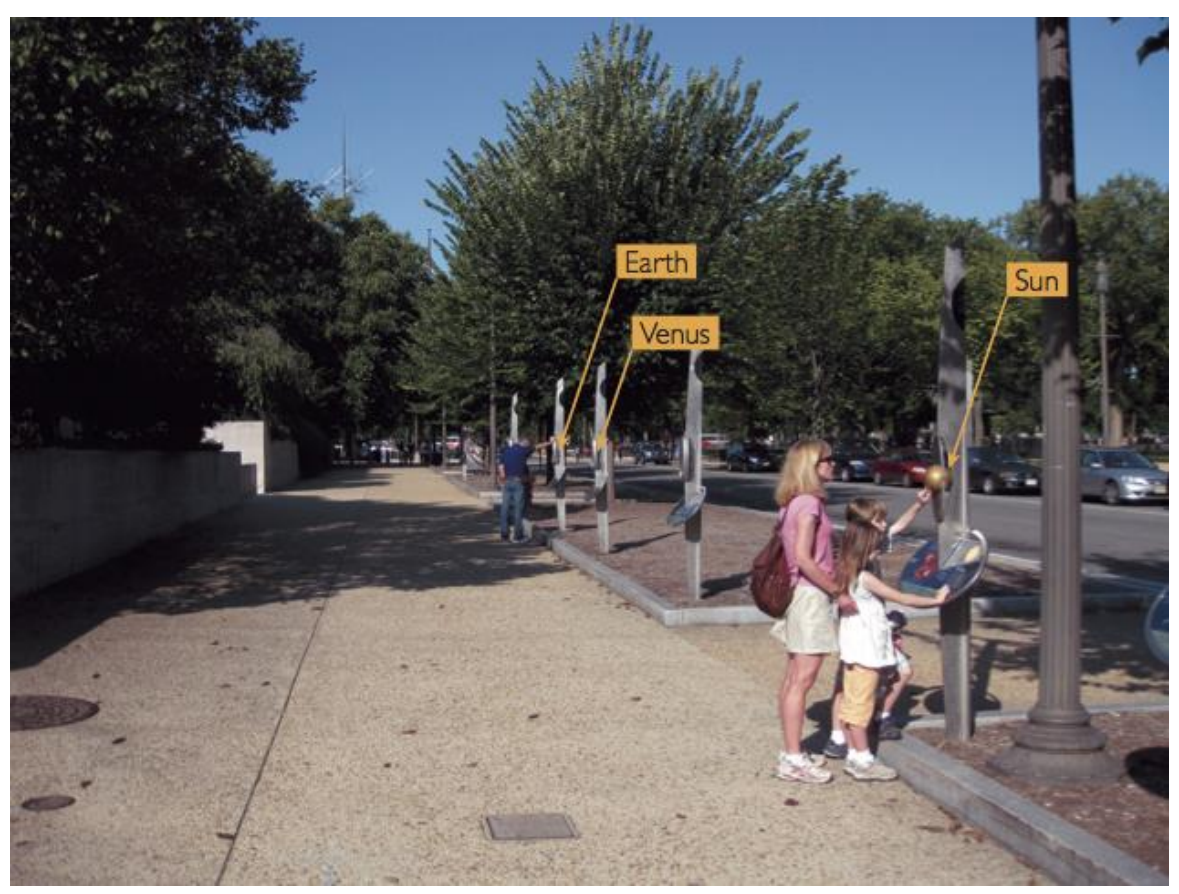

Figure 1. The Voyage Scale Model Solar System (scale: 1 to 10 billion), which begins just outside the National Air and Space Museum (the building to the left) in Washington, DC. As one example of the kinds of activities such models support, I use this photo when I speak on global warming to help explain why Venus's closer distance to the Sun is not enough (by itself) to account for its extreme heat, which then allows me to explain how the real reason must be the carbon dioxide induced greenhouse effect.

I entered graduate school in astrophysics in 1981 (University of Colorado, Boulder, or "CU"). ${ }^{1}$ My experience in elementary and middle school teaching made me a sought-after teaching assistant, and by my third year I was teaching my own courses, typically at least two every semester. This teaching led me to realize that most college students were not in general any better at QR than my elementary and middle school students. For example, most college students were no better at interpreting numbers like "million" and "billion" than the elementary school students, nor did they know how to properly interpret common types of statistical statements and graphs. ${ }^{2}$ This meant that I could repurpose (and expand on) much

\footnotetext{
1 My switch from biophysics as an undergrad to astrophysics in grad school was a direct result of Carl Sagan's original Cosmos series, which aired in Fall 1980. It's worth noting that Sagan's series included many segments that focused on ideas that we would now count as supporting numeracy and quantitative reasoning.

2 To be more specific on the number sense: Both kids and adults are usually well aware that 10 is ten times as large as 1; 100 is ten times as large as 10; and 1,000 is ten times as large as 100. From these, the meanings of "ten thousand" and "one hundred thousand" are fairly obvious. But beyond that, I don't think it's an exaggeration to say that most people see little difference between million, billion, and trillion aside from their first letters.
} 
of the material from my summer school program to use with my college students. One such repurposing was my work on model solar systems, which ultimately led to the installation on CU's campus of the Colorado Scale Model Solar System (and later to the Voyage model in Figure 1), opened and dedicated in 1987 as a memorial to the Challenger astronauts. ${ }^{3}$

The result of all the above was that by the time I received my Ph.D. in astrophysics in 1987, at least a few faculty and administrators were familiar with my teaching and outreach work. Coincidentally, this was also the time when the College of Arts and Sciences was embarking on a core curriculum revision, which brings me to the next part of the story.

\section{QR Course Development at the University of Colorado}

In the early-1980s, CU's College of Arts and Sciences decided it was time to revamp its core curriculum. The College established a committee, chaired by thenAssociate Dean Charles Middleton (an historian by training), charged with generating the proposed new requirements. The stated goal was to make a core curriculum that would answer the question: "What will broadly educated citizens need to know and need to be able to do in the $21^{\text {st }}$ century that we as a responsible faculty should compel them to learn and develop skills to undergird their long term success in the approaching century?" Following discussions and approval by the full college faculty (which required a $2 / 3$ vote), the core curriculum approved in 1984 (and set to take effect in 1988, so as not to impact then-current students) included a new requirement that students pass a course that would demonstrate proficiency in "quantitative reasoning and mathematical skills."4 Given the timing, this may well have been the first instance of a college creating a QR requirement.

By early 1987, the College had established an interdisciplinary faculty committee to work out the details of the new requirement, including defining what was meant by "quantitative reasoning and mathematical skills" and identifying courses that would satisfy the requirement. ${ }^{5}$ According to what I was told later,

3 More information about the Colorado Scale Model Solar System and how it led to the Voyage model is posted on my web site at www.jeffreybennett.com/CSMSS.

4 As the committee Chair, Dr. Middleton led discussions that finalized the QR requirement and shepherded it through the approval process, which was no easy task given the need for $2 / 3$ of faculty across all disciplines to approve it. However, I recently contacted him to get the details on this back story, and he says he was not the person who first proposed including the QR requirement, though he strongly supported it. Unfortunately, we have so far been unable to track down exactly who proposed the requirement.

5 Committee Chaired by John Williamson (Mathematics). Other faculty members: Otomar Bartos (Sociology), Steve Bernstein (Biology), Gary Bradshaw (Psychology), Michael Breed (Biology), 
during one of the early meetings of this committee, the members decided that they should seek outside help from someone with experience in teaching QR-type material. One of the committee members happened to be an astronomer (Andrew Hamilton) who was aware of my teaching experience and work on the model solar system, and at his behest they reached out to me, and that is how my more formal involvement in QR began.

As you might guess, the committee meetings had a lot of spirited discussion and debate. In the end, the committee adopted the following language (which appeared in the College's 1988 course catalog) to define the new requirement:

Courses which meet this requirement provide students with the analytical tools needed in numerous other courses in the curriculum. They also help students acquire the reasoning skills necessary to assess adequately much of the data which will confront them in their daily lives.

More specifically, all courses are designed to assure that by the beginning of their second year at the University students are able to construct a logical argument based on the rules of inference; to analyze, present, and interpret numerical data; to estimate orders of magnitude as well as obtain exact results when appropriate; and to solve problems by mathematical methods. ${ }^{6}$

You probably also won't be too surprised to learn that another outcome of the committee work was the decision that no existing courses truly met the spirit of this new QR requirement. (For practical reasons, existing courses including algebra, calculus, and a few others were nevertheless deemed sufficient.) The committee therefore decided that a new, QR-focused course should be created, and this meant someone would have to do this. As a newly minted Ph.D. who didn't yet have a more permanent job, the rest of the committee turned to me. It's worth noting that the fact that my degree was in astrophysics rather than mathematics was actually considered a plus by the committee members, since they wanted the course to reflect an interdisciplinary point of view. So that is how an astronomer ended up teaching one of the first-ever QR courses.

We piloted the QR course with a single lecture section in Fall 1988, with committee members Tom Swain and Steve Bernstein helping me develop the initial curriculum and co-teaching this first class. The success of the pilot led the College to formally establish an interdisciplinary QR program, modeled administratively after the College's existing, interdisciplinary writing program. I was hired as the Director of this new program, which debuted in Fall 1989.

Greg Carey (Psychology), Gary Gaile (Geography), Andrew Hamilton (Astronomy), John Hodges (Mathematics), Robert MacRae (Mathematics), Richard Roth (Mathematics), and Tom Swain (Biology).

6 The plan to have students meet the QR requirement in their first year was intended to make it possible for higher level courses across the curriculum to then build on these skills. Unfortunately, there was no enforcement mechanism, so in practice it became a graduation rather than first-year requirement. 
The new QR program had tremendous support from the Dean's office (especially from Dean Charles Middleton and Associate Dean Mike Shull), which provided a budget that allowed me to hire approximately a dozen teaching assistants (both undergrads and graduate students) drawn from departments across campus. The initial course structure had 2 hours of lecture (large lecture classes, typically $150+$ students) and 2 hours of discussion ( 25 students) each week; I did the lectures while the TAs ran the discussion sections. We also met weekly for long meetings in which we discussed how the course was working and planned improvements both for subsequent weeks and for future incarnations of the course. In this way, many of the TAs played a huge role in shaping the course and the textbook that arose out of it. ${ }^{7}$

I ran the QR program for its first three semesters (through Fall 1990). At that point, I received a "too good to pass up" offer to take a 2-year Visiting Senior Scientist position at NASA Headquarters (Washington, DC), in which I had the opportunity to help create innovative new programs to bring the space research and education communities together. I therefore took leave from $\mathrm{CU}$, handing off my position as Director of the $\mathrm{QR}$ program to a close colleague and fellow astronomer, Cherilynn Morrow. By this point, we had also secured a grant from the National Science Foundation to support our QR curriculum development efforts. ${ }^{8}$ Fortunately, the nature of my "Visiting" position at NASA allowed me to continue with my role as the Principal Investigator on this grant, so even though I was no longer teaching the course, I remained deeply involved in its development.

\section{Textbook Evolution}

When I first accepted the job of teaching the new QR course, I did not realize the pioneering nature of CU's effort, and I had naively assumed that I'd be able to find some kind of textbook to fit the curriculum. Of course, that wasn't the case. For the pilot course, we were able to provide readings for some of the course topics with John Allen Paulos's Innumeracy (Hill and Wang 1988) and a "Schaum's Outline" in statistics that had been written by Steve Bernstein (the QR committee member who helped teach the pilot course). However, I felt that the lack of a "real" textbook

\footnotetext{
7 Among the TAs who contributed the most were: Megan Donahue (who later became co-author of my astronomy text), Hal Huntsman, John Supra, David Wilson, Mark Anderson, Debbie Segal, Bev Boydston, Jon Goldberg, Laura Loughry, David Theobald, Jon Dowling, Karen Herendeen, and Joe Kunches.

8 The grant (NSF grant number USE-915060) came through the NSFs program for Undergraduate Course and Curriculum Development. Our funded proposal was titled "Quantitative Reasoning and Mathematical Skills: A Prototype Course in Mathematical, Scientific, and Technological Literacy;" I was the PI, with Cherilynn Morrow and Associate Dean Mike Shull as co-PIs. The \$97K grant went primarily toward creating computer-based projects and activities to support the QR goals.
} 
with a coherent approach to the subject matter was one of the biggest shortcomings of the pilot course. As a result, going into my position as Director of the new program in Fall 1989, I decided to write my own set of notes to serve as a textbook.

For the first couple of semesters, I wrote up these notes as we went along, photocopying them in the astronomy department office and handing them out to students. By Fall 1990, these notes had grown extensive enough ( 200 pages) that the department asked me to instead take them to the bookstore, where they would be copied and sold to students, so that term, the bookstore shelves carried a spiral bound volume entitled Quantitative Reasoning and Mathematical Skills with my name as the author. I continued to revise and expand the notes for each new semester, and by the beginning of 1993 they had reached about 400 pages.

The presence of the spiral bound volumes on bookstore shelves caused publisher reps to take notice, and I soon had numerous publishers talking to me about a textbook contract. I ultimately signed with publisher Addison-Wesley in 1993, and since Cherilynn Morrow had by that point been teaching the course for two years, I invited her to join in as a co-author. ${ }^{10}$ Shortly after signing, our editor (Bill Poole) became concerned about how a mathematics text would be received if it was written only by two astronomers, so he asked me to consider adding a mathematician as co-author. I'd recently met Bill Briggs and learned of the very similar work he had been doing on the CU-Denver campus (see his companion article), so I asked if he'd join in. He agreed, which meant we had both his prior work and my existing notes from which to build the textbook.

The primary reason I signed with Addison-Wesley (over other publishers) was that they were the only publisher who truly seemed to understand that they were signing a textbook for a market that did not really exist (since aside from our course at $\mathrm{CU}$, there were not yet any other QR courses that either we or they were aware of). They also expressed a deep belief in the importance of our QR efforts, which came with a clear willingness to put in the work and financial resources necessary to try to promote the spread of QR courses. This led them to a strategy in which, rather than the normal path of simply putting out a first edition, they instead had us start with two "market building" editions. The first, published in 1995, was entitled Quantitative Literacy, Class Test Edition. The editors and sales reps used this edition to reach out to colleges where they sensed some interest in a QR-type class, and managed to convince at least a couple dozen instructors to try it out. ${ }^{11}$

9 Addison-Wesley was already owned by Pearson at the time, but published under its own imprint until the mid-2000s. That is why early editions of our textbook carry the Addison-Wesley imprint while more recent editions say Pearson.

10 Cherilynn contributed many important ideas and insights to the early development of the textbook, but she soon took on other new responsibilities that prevented her from being as involved as she'd hoped to be. As a result, she withdrew from the textbook team after about two years.

11 I do not have a complete list of the early adopters, but they included instructors at Marshall University, Cal State Monterrey Bay, Essex Community College, LaGuardia Community College, 
Users of the Class Test Edition provided us with extensive and constructive feedback, which led to our next iteration, published in 1996 with the title Quantitative Reasoning: Mathematics for Citizens in the $21^{\text {st }}$ Century, Preliminary Edition. This volume built the market further, and therefore provided us with even more feedback about how to improve the book.

The Preliminary Edition was successful enough that the publisher felt the project and market were mature enough for a true first edition. Bill Briggs and I got back to work, and the "first edition" came out in late 1998 with a new title, Using and Understanding Mathematics: A Quantitative Reasoning Approach. Because it was now a "real" textbook, the number of adoptions grew to several hundred, and the associated feedback led us to revise the book quite extensively when we moved on to the second edition in 2001. It was at that point that we put the book into a 5part structure that we have stuck with ever since:

- Part 1 (which consists of chapters 1 and 2) focuses on "Logic and Problem Solving."

- Part 2 (chapters 3 and 4) is "Quantitative Information in Everyday Life," focusing on basic ideas of numeracy and on managing money, including taxes and the federal budget.

- Part 3 (chapters 5 to 7) is "Probability and Statistics," with a focus on statistical reasoning (as opposed to calculation), including how to read graphs and how to interpret statistics and probability in the news and in daily life.

- Part 4 (chapters 8 to 10) is titled "Modeling," and here we focus on the basic concepts and uses of models, with emphasis on linear models, exponential models, and geometric models.

- Part 5 is our "Further Applications," where we include topics such the role of mathematics in the fine arts and the mathematics of voting and redistricting (including gerrymanders).

You may notice that this structure very closely mimics the original statement (given earlier) from the $1988 \mathrm{CU}$ course catalog describing the content of courses that meet the QR requirement.

Bill Briggs and I have continued to revise, update, and improve the book ever since. These revisions aim to keep the content current and relevant to students. For example, after the 2008 recession, we included discussion of its causes and how a more quantitatively literate society might have avoided the recession. And today, as we work on the $8^{\text {th }}$ edition to come out in early 2022, we are including numerous examples and activities relating to the COVID-19 pandemic. While exact numbers are hard to come by, we estimate that some edition of our textbook has by now been used by close to 2 million students. ${ }^{12}$ We hope that with continued development, we can reach many more in the future.

Millersville University, the University of Hawaii, the University of Texas San Antonio, the University of Wisconsin Madison, and BYU-Idaho (known as Ricks College at the time).

12 This very rough estimate is based on publisher numbers indicating 600,000 new book sales. Estimated student usage is roughly triple that through a combination of sharing and used book sales. 


\section{Other Career Connections}

I've never actually taught a QR course again since leaving the CU position at the end of 1990, but my ongoing work on the textbook has kept it one of the main focal points of my career. ${ }^{13}$ Meanwhile, work on the QR text also led to many other opportunities.

On the writing side, the fact that I was an astronomer (and had taught introductory astronomy many times) led my editors at Addison-Wesley to ask if I'd also be interested in writing an astronomy textbook. I was, and with the help of three co-authors (Megan Donahue, Nick Schneider, and Mark Voit), the first edition of The Cosmic Perspective was published simultaneously with the first edition of Using and Understanding Mathematics in late 1998. ${ }^{14}$ The editors were apparently pleased enough with these books that they wanted more. As a result, Bill Briggs and I were recruited (along with Marty Triola) to write Statistical Reasoning for Everyday Life (now in $5^{\text {th }}$ edition), and I also became lead author of a textbook in astrobiology, Life in the Universe (now in $4^{\text {th }}$ edition).

Meanwhile, my elementary school teaching experience had long had me thinking about writing science books for children, and this opportunity opened when a few of the people who worked on my textbooks at Addison-Wesley offered to help me start my own publishing imprint for this purpose. They provided the expertise to make my venture into self-publishing look professional, and I've now used this imprint - Big Kid Science (www.BigKidScience.com) - to publish six science-themed children's books. ${ }^{15}$ I've also written several books for educators and the general public.

I've also been involved in several other projects in STEM education, all of which have a significant $\mathrm{QR}$ component. In hopes that some readers may be interested in these, I'll briefly list the major ones here:

- Story Time From Space (www.storytimefromspace.com): This project launches science-

13 I had hoped to resume my position as Director of the QR program when I returned to CU in 1993, but by that point the program was being moved to be administered under the mathematics department. In one of those strange ironies of university politics, this meant that the Director was now required to have a Ph.D. in mathematics, and since mine was in astrophysics, I was ineligible for the position - even though they continued to use my textbook.

14 It's worth noting that here, again, Carl Sagan played a huge role, although he was never aware of it. My major frustration with existing astronomy textbooks (and there were many) was that none of them captured the excitement of the subject that Sagan had so effectively conveyed in his Cosmos series. As a result, much like the notes I was writing up for the QR course, I had also been writing up my own notes for my astronomy students, so I was very excited when Addison-Wesley gave me the opportunity to write in that subject as well.

15 These books use fictional stories in which I've built in lessons on science, which are expounded upon in sidebars or figure captions. The titles are: Max Goes to the Moon, Max Goes to Mars, Max Goes to Jupiter, Max Goes to the Space Station, The Wizard Who Saved the World, and I, Humanity. 
themed books to the International Space Station, where they are read aloud by astronauts, with videos posted for kids on Earth. The project also creates science demos that the astronauts perform in the weightless environment. I became involved in this project after its founders chose my children's books as the first to be launched for the program.

- The Totality app: We've created the only free app that provides fully interactive, highresolution maps for upcoming solar eclipses, along with educational background about eclipses. This should be especially useful for two fantastic eclipses coming soon in the USA: an annular eclipse crossing the western half of the country on Oct. 14, 2023, and a total solar eclipse crossing the eastern half on April 8, 2024. More information and download links at www.bigkidscience.com/eclipse/.

- Scale model solar systems: I continue to work closely with the Voyage National Program to spread scale model solar systems (like that in Fig. 1) around the country and world. In fact, later this year (2021) we will be installing a new Voyage model to replace our now 34-year-old Colorado Scale Model Solar System. I encourage all Numeracy readers to consider installing one of these models on your campus or in your community. You can contact me for more information.

- Public understanding of global warming: I began incorporating the topic of global warming into my teaching starting in the early 1980s, which is why it has always been included in several places in our QR textbooks. More recently, I have decided to focus more heavily on this topic, writing books about it for both children (The Wizard Who Saved the World) and the general public (A Global Warming Primer); the latter is freely posted at www.globalwarmingprimer.com.

- Faculty Workshops and Public Speaking: I frequently talk about math and science teaching with both college and K-12 faculty (based around my books On Teaching Science and Math for Life), and also speak often to school children and to general public audiences. Prior to the pandemic shutdowns, I was offering to come at my own expense to speak at any venue where I could be assured of a large audience for a public talk on global warming, along with school visits for kids and faculty workshops. I hope to resume this program post-pandemic. More information at http://www.jeffreybennett.com/visit.

- Middle school science: Decades of teaching and writing have led me to conclude that the biggest failing in our STEM education system occurs in middle school, in part due to a lack of quality curriculum materials. I've therefore recently begun to write my own middle school science curriculum, starting with Earth and Space Science (most commonly taught in $8^{\text {th }}$ grade, following physical science and life science in the prior years). This curriculum is available free and online (www.grade8science.com). I hope you will check it out and spread word about it to middle school teachers and administrators.

Finally, I'll note that while my writing and projects cross over disciplines and age groups, they all share a common theme of improving general math and science literacy, and in that sense I hope they will represent at least some small contribution to putting us on the right side of the "race between education and catastrophe" of the opening quote from H.G. Wells. I thank you for your time in reading this retrospective, and encourage you to think big about the ways in which your own work will help toward the same goal. 


\section{Bibliography (of Latest Editions) Textbooks}

Using and Understanding Mathematics: A Quantitative Reasoning Approach, $7^{\text {th }}$ edition, 2018, Pearson ( $8^{\text {th }}$ edition to be released early 2022)

Statistical Reasoning for Everyday Life, $5^{\text {th }}$ edition, 2017, Pearson

The Cosmic Perspective, $9^{\text {th }}$ edition, 2020, Pearson; also available in shorter versions The Essential Cosmic Perspective, $9^{\text {th }}$ Edition, 2021, and The Cosmic Perspective-Fundamentals, $3^{\text {rd }}$ Edition, 2020.

Life in the Universe, $4^{\text {th }}$ edition, 2016, Pearson

\section{Books for Educators}

On Teaching Science: Principles and Strategies That Every Educator Should Know, 2014, Big Kid Science

Math for Life: Crucial Ideas You Didn't Learn in School, 2014, Big Kid Science

\section{Books for the General Public}

A Global Warming Primer: Answering Your Questions About the Science, the Consequences, and the Solutions, 2016, Big Kid Science

What is Relativity?-An Intuitive Introduction to Einstein's Ideas, and Why They Matter, 2014, Columbia University Press

Beyond UFOs: The Search for Extraterrestrial Life and Its Astonishing Implications to Our Future, 2008/2011, Princeton University Press

\section{Books for Children}

Max Goes to the Moon, Planetarium Show Edition, 2013, Big Kid Science Max Goes to Mars, Second Edition, 2015, Big Kid Science Max Goes to Jupiter, Second Edition, 2018, Big Kid Science Max Goes to the Space Station, 2014, Big Kid Science The Wizard Who Saved the World, 2012, Big Kid Science I, Humanity, 2016, Big Kid Science 